\title{
Behavioural and Emotional Functioning of Adolescents with Mild Intellectual Disability: Perspectives from Home and School
}

\author{
Nigel V. Marsh ${ }^{1 *} \&$ Siau H. $\mathrm{Ng}^{2}$ \\ 'Department of Psychology, Sunway University \\ 2Department of Psychology, James Cook University
}

\begin{abstract}
This study examined the frequency and severity of behavioural and emotional disturbances in adolescents with mild intellectual disability. The 50 adolescents, aged between 12 and 16 years, attended a special school in Singapore. Information on the adolescents' functioning was obtained from their parent/primary carer and their class teacher, who both completed the relevant version of the Developmental Behaviour Checklist. The results showed that, in addition to difficulties related to their intellectual disability, $22 \%$ to $27 \%$ of students displayed significant behavioural and emotional disturbances. Disruptive/Antisocial behaviours were the most frequently reported problems. But communication disturbances were reported as being the most severe problems. Carers and teachers reported the same pattern in the relative frequencies of the different types of problems. However, primary carers consistently reported a higher frequency than teachers for all types of problems. Implications of these findings for the consistent management of the adolescents' challenging behaviour are discussed.
\end{abstract}

Keywords: Mild Intellectual Disability, Adolescents, Challenging Behaviour, Special Education, Developmental Behaviour Checklist (DBC).

Funcionamiento emocional y conductual de los adolescentes con discapacidad intelectual leve: perspectivas desde el hogar y la escuela.

Resumen. Este estudio examinó la frecuencia y gravedad de los trastornos conductuales y emocionales en adolescentes con discapacidad intelectual leve. Los 50 adolescentes, de entre 12 y 16 años, asistieron a una escuela especial en Singapur. La información sobre el funcionamiento de los adolescentes se obtuvo de su cuidador primario y su maestro de clase, quienes completaron la versión pertinente de la Lista de Comportamiento del Desarrollo. Los resultados mostraron que, además de las dificultades relacionadas con su discapacidad intelectual, entre el $22 \%$ y el $27 \%$ de los estudiantes presentaron trastornos conductuales y emocionales significativos. Los comportamientos disruptivos / antisociales fueron los problemas más frecuentemente reportados. Sin embargo, los trastornos de la comunicación fueron reportados como los más graves. Los cuidadores y los maestros reportaron el mismo patrón en las frecuencias relativas de los diferentes tipos de problemas. Sin embargo, los cuidadores primarios siempre reportaron una frecuencia mayor que los maestros para todo tipo de problemas. Se discuten las implicaciones de estos hallazgos para el manejo consistente del comportamiento desafiante de los adolescentes.

Palabras clave: Discapacidad Intelectual Leve, Adolescentes, Conducta Desafiante, Educación Especial, Lista de Verificación del Comportamiento del Desarrollo (DBC).

It has been reported that children and adolescents with an intellectual disability (ID) have a three to seven times increased risk of

Received: 30/04/2017 - Accepted: 15/05/2017 - Avaliable online: 20/06/2017

*Correspondence: Nigel V. Marsh.

Department of Psychology, Sunway University, N. 5 Jalan

Universiti, Bandar Sunway.

Postcode: 47500, Selangor Darul Ehsan, Malaysia.

E-mail: nigelm@sunway.edu.my

Marsh, N. V, \& Ng, S. H. (2017). Behavioural and Emotional Functioning of Adolescents with Mild Intellectual Disability: Perspectives from Home and School. Journal of Psychology and Education, 12(2), 76-84,

https://doi.org/10.23923/rpye2017.12.146 behavioural and emotional disorders when compared to peers with no ID (Alimovic, 2013; Einfeld, Ellis, \& Emerson, 2011). This challenging behaviour in young people with ID decreases only slowly over time and remains high into young adulthood (Einfeld et al., 2011 ). This suggests that emotional and behavioural disorders in young people with ID 
are a significant and persistent problem that requires effective intervention plans. Einfeld and Tonge (1996a) stated that such difficulties decrease the well-being of the affected person, increase distress to carers and the likelihood of institutionalization, as well as reduce social integration and later employment.

Reasons for variation in the estimates of the prevalence of challenging behaviour in young people with ID have been attributed to the definition and operationalization of both ID (White, Chant, Edwards, Townsend, \& Waghorn, 2005) and psychopathology (Whitaker \& Read, 2006). In addition, there is wide variation in the methods of data collection across studies (de Ruiter, Dekker, Douma, Verhulst, \& Koot, 2008) These three factors may account for the inconsistent findings within existing literature and make it difficult to compare findings across studies.

The lack of differentiation of severity of ID may have resulted in different prevalence rates across studies. It has been found that specific types of problems tend to occur more frequently in people with mild ID, as compared to those with moderate and severe ID. For example, disruptive and antisocial behaviours, aggressive behaviours, conduct disorder, anxiety and mood disorders, and psychosis have been found to be more prominent in people with mild ID (Dekker, Koot, van de Ende, \& Verhulst, 2002; Dykens, 2000; Einfeld \& Tonge, 1996b; Koskentausta \& Almqvist, 2004; Koskentausta, livanainen, \& Almqvist, 2007; Molteno, Molteno, Finchilescu, \& Dawes, 2001; Myrbakk \& von Tetzchner, 2008). There is a higher association of tantrums and self-injury with depression in the mild ID group (Myrbakk \& von Tetzchner, 2008). Communication disturbance was also found to be more prominent in young people with mild ID compared to the severe and profound ID group (Einfeld \& Tonge, 2002). In comparison, people with moderate to severe ID present with higher rates of self-absorbed and autistic-like behaviours, withdrawn behaviours, thought problems, and behavioural disorders such as self-injury, aggression and destructive behaviour (Dekker et al., 2002; Dykens, 2000; Einfeld \& Tonge, 1996b; Jacobson, 1982; Molteno et al., 2001 ; Myrbakk \& von Tetzchner, 2008; Ruddick, Davies, Bacarese-Hamilton, \& Oliver, 2015). Depression in the severe and profound ID group is associated with aggression, tantrums and screaming (Myrbakk \& von Tetzchner, 2008). However, Dekker et al. (2002) found that similar to children and adolescents with mild ID, young people with moderate to severe ID also presented with high rates of both social and attention problems. The mechanisms underlying the relationship between severity of ID and the nature of behavioural problems remain unclear (Munir, 2016).

Developing an international consensus on a common approach to the classification and diagnosis of the range of emotional and behavioural disturbances exhibited by people with ID has proved difficult (Tonge, 2007). The application of current psychiatric diagnostic systems (e.g., Munir, 2016) is not useful as they attempt to apply the concept of mental disorder to a population whose behaviour is already restricted and unusual when compared to the general population. Sturmey (2007) suggested that it is often difficult to ascertain if a change in behaviour has occurred beyond the already present challenging behaviour found in people with ID. Professionals in the field of ID have moved from diagnosing and treating mental disorders to working with symptoms, and appropriate assessment instruments have been developed (Einfeld \& Tonge, 2002; Reardon, Gray, \& Melvin, 2015). In addition, there is recent evidence that the presence of challenging behaviour in children and adolescents with ID is to a large extent a function of an interaction between the individuals and the environment, rather than due to a mental disorder or even the presence of ID itself (Didden, 2007; Dworschak, Ratz, \& Wagner, 2016; Jacobs, Woolfson, \& Hunter, 2016).

Despite the methodological difficulties, prevalence studies within the ID population are necessary and important as they inform about the scope of the problem as well as provide specific information to allow for service planning to meet the needs of this group (Hassiotis \& Turk, 2012; Parmenter, 
Harman, Yazbeck, \& Riches, 2007). Some research indicates that while observers rate adolescents with ID as having more problems than typically developing adolescents, this is not consistent with the self-reports from both typically developing adolescents and adolescents with ID (Pavlovic, Zunic-Pavlovic, \& Glumbic, 2013).

In the present study, adolescents with mild ID were specifically identified for examination. This was done to ascertain if the overall higher prevalence of emotional and behavioural difficulties in people with ID applied to this particular sub-group of people with mild ID. In addition, the study sought to identify if specific types of difficulties were more common among adolescents with mild ID. The severity level of the different types of challenging behaviour that occurred was also examined.

So that a more complete picture of problem behaviour can be obtained, Tasse and Lecavalier (2000) emphasized the importance of collecting information from multiple sources across different contexts for people with ID. As adolescents tend to behave differently in different settings, they recommended that different informants should be included when examining adolescent emotional and behavioural disturbances. Similarly, Winterbottom, Smith, Hind, and Haggard (2008) found low correlations between parents' and teachers' reports on children's behaviour, and suggested that this is a result of strong divergence in perspectives, or situation-dependent behaviours. However, de Ruiter et al. (2008) highlighted that problem behaviours in adolescents with ID are highly stable, suggesting that emotional and behavioural disturbances may be manifested in a consistent manner across different settings. Research in other areas of disability has demonstrated that to increase the effectiveness of interventions a shared perspective on the nature and prevalence of problem behaviours is important (Marsh \& Kersel, 2006).

Einfeld and Tonge (2002) found that, except for Communication Disturbance, parents and teachers ranked the order of subscale problems on the Developmental Behaviour Checklist (DBC) similarly. Although both sets of respondents identified similar behaviours as being problematic, they differed in their perception of the severity of the problems. Einfeld and Tonge (2002) reported that parents consistently scored their children as being more disturbed compared to teachers. In a review of the literature, Tasse and Lecavalier (2000) found mixed findings regarding the consistency with which parents and teachers rate problem behaviours of children.

The overall aim of the present study was to examine the prevalence and severity of behavioural and emotional disturbances in adolescents with mild ID. To ensure that comprehensive information was obtained on the adolescents' challenging behaviours across a range of settings, both parents/ primary carers and teachers served as informants. A comparison was made between parent and teacher reports for both the relative (ranking between types of behaviours) and absolute (comparison for a specific behaviour) frequencies of the different types of challenging behaviour. The severity of the different types of problems was also described and compared across parents and teachers.

\section{METHOD}

\section{PARTICIPANTS}

The sample consisted of 50 students who had previously been diagnosed with mild ID and who were attending a school in Singapore managed by the Association for Persons with Special Needs. The mean age of the students was 13.78 years $(S D=1.08$, range $=12-16$ years). There were 29 (58\%) males and 21 (42\%) females in the sample. The sample was of mixed ethnicity: Chinese (60\%), Malay (26\%), Indian (10\%), and 'other' (4\%). The majority of the students lived with at least one parent ( $n=49)$, with the remaining student staying with extended family.

The respondents for this study were the parents/primary carers and class teachers of the 50 students. Forty-nine carers returned all forms and the majority of the carers were female ( $n=34,69 \%$ ). The majority of the carers were the mothers of the 
students $(n=33,67 \%)$, followed by fathers $(n=11,22 \%)$. The remaining carers were brothers $(n=3,6 \%)$, a sister, and an uncle.

Twelve teachers provided information on 48 students. Teacher respondents were all class teachers of the students, and had known the students for at least three months. The majority of the teachers were female $(n=11,92 \%)$.

\section{MEASURES}

The Developmental Behaviour Checklist (DBC) (Einfeld \& Tonge, 2002) is a standardized instrument for the assessment of a broad range of behavioural and emotional disturbances in children and adolescents aged 4 to 18 years, with developmental and intellectual disabilities. The DBC-P (Parent/Primary Carer Version) is a 96-item questionnaire to be completed by the primary carer. This carer must have known the person for at least 6 months. The DBC-T (Teacher Version) is a 94 -item questionnaire to be completed by a teacher or teacher aide who has known the young person for at least 2 months.

Each item on the DBC describes an observable behaviour. The item is given a rating of 0 (not true as far as you know/not applicable), 1 (somewhat or sometimes true), or 2 (very true or often true) depending on the respondent's perception of the degree of the presence of a particular behaviour in the young person with developmental or intellectual disability. Therefore, higher scores indicated a higher frequency of a specific behaviour. Normative, reliability, and validity data were obtained from a sample of 454 carers and 640 teachers (Einfeld \& Tonge, 2002).

A Total Behaviour Problem Score is derived from the addition of scores of all items. This provides an overall indication of how severe the behavioural and emotional problems are in the individual. The DBC also provides subscale scores measuring disturbances on the five dimensions of Disruptive/Antisocial (e.g., manipulates, abusive, irritable, kicks, lies, light fires), Self-Absorbed (e.g., eats nonfood, hums, preoccupied with trivial items such as strings and twigs), Communication Disturbance (e.g., echolalia, perseveration, talks to self), Anxiety (distressed if alone, fears, phobias, cries easily), and Social Relating (does not show affection, resists cuddling, aloof). Normative data is used to convert the obtained scores to a standard score with a mean of 50 and a standard deviation of 10 (Einfeld \& Tonge, 2002).

\section{PROCEDURE}

Ethical approval for this study was obtained from the James Cook University Human Research Ethics Committee. All students within the age of 12 to 16 years in the school were given an invitation letter to participate in the research to pass to their parents or guardians. Those carers who agreed to participate were posted the relevant forms which they completed and returned to the school.

The class teachers of students whose caregiver returned signed informed consent forms were then approached for their consent to participate in the study. All teachers approached met the inclusion criteria of having taught the student for at least three months, and all agreed to participate in the study.

\section{DATA ANALYSIS}

Data analyses were performed using PASW Statistics 18 (SPSS Inc., 2009). Independent sample t-tests were used to examine for significant differences between carers and teachers in the average frequency of problems over the five subscales. The effect size statistic of eta squared $\left(\eta^{2}\right)$ was interpreted as $.01=$ small, $.06=$ moderate, and $.14=$ large (Cohen, 1988). These mean scores were also used to determine the relative frequency of problems across the five subscales for both carers and teachers.

Interpretation of the obtained scores was undertaken using the clinical cut-off scores provided for the Total Behaviour Problem Score (Einfeld \& Tonge, 2002). For the purposes of the current study the cut-off score for the five subscales of the DBC was set at one standard deviation above the mean of the normative sample. 


\section{RESULTS}

\section{FREQUENCY OF BEHAVIOURAL EMOTIONAL PROBLEMS}

The order, from most frequent to least frequent, for type of problem as reported by parent/primary carer was: Disruptive/ Antisocial, Self-Absorbed, Communication Disturbance, Social Relating, and Anxiety. The order, from most frequent to least frequent, for type of problem as reported by teachers was also: Disruptive/Antisocial, Self-Absorbed, Communication Disturbance, Social Relating, and Anxiety (Table 1). Therefore, both carers and teachers held a shared perception of the relative frequency of the five different types of problems displayed by the students.

However, carers reported a significantly higher frequency than teachers for all five types of problems: Disruptive/Antisocial ( $p=.004)$, Self-Absorbed ( $p=.005)$, Communication Disturbance $(p=.005)$, Anxiety $(p<.001)$, and Social Relating ( $p=.003$ ) (Table 1). The magnitude of the differences in the means was moderate for Disruptive/Antisocial and Self-Absorbed $\left(\eta^{2}=.11\right.$ for both), and for Communication Disturbance and Social Relating $\left(\eta^{2}=.10\right.$ for both). The magnitude of the difference in the means for Anxiety was large $\left(\eta^{2}=.20\right)$. Therefore, although primary carers and teachers agreed on the relative frequency of the five types of problems, for all five types of problems carers reported a higher average frequency.

\section{PREVALENCE OF SIGNIFICANT BEHAVIOURAL AND EMOTIONAL PROBLEMS}

The Total Behaviour Problem Score gives an overall measure of behavioural and emotional disturbance and scores above the cut-off indicate that the young person will be regarded as having "major behavioural or emotional problems" (Einfeld \& Tonge, 2002). This score cannot be calculated unless all items have been answered. Only 28 (56\%) of parent/primary carers and 26 (52\%) of teachers completed all the items on the DBC. For those students where the DBC was completed in full, reports from the primary carers indicated that $22 \%$ of the students had major problems. In contrast, the reports from the teachers indicated that $27 \%$ of the students had major problems.

Across the five types of problems both carers and teachers agreed that communication disturbance was the most likely to be a significant problem. They also agreed that anxiety was the second most common significant problem. They did not agree on the third and fourth most common significant problem, but both agreed that being self-absorbed was least likely to be a significant problem.

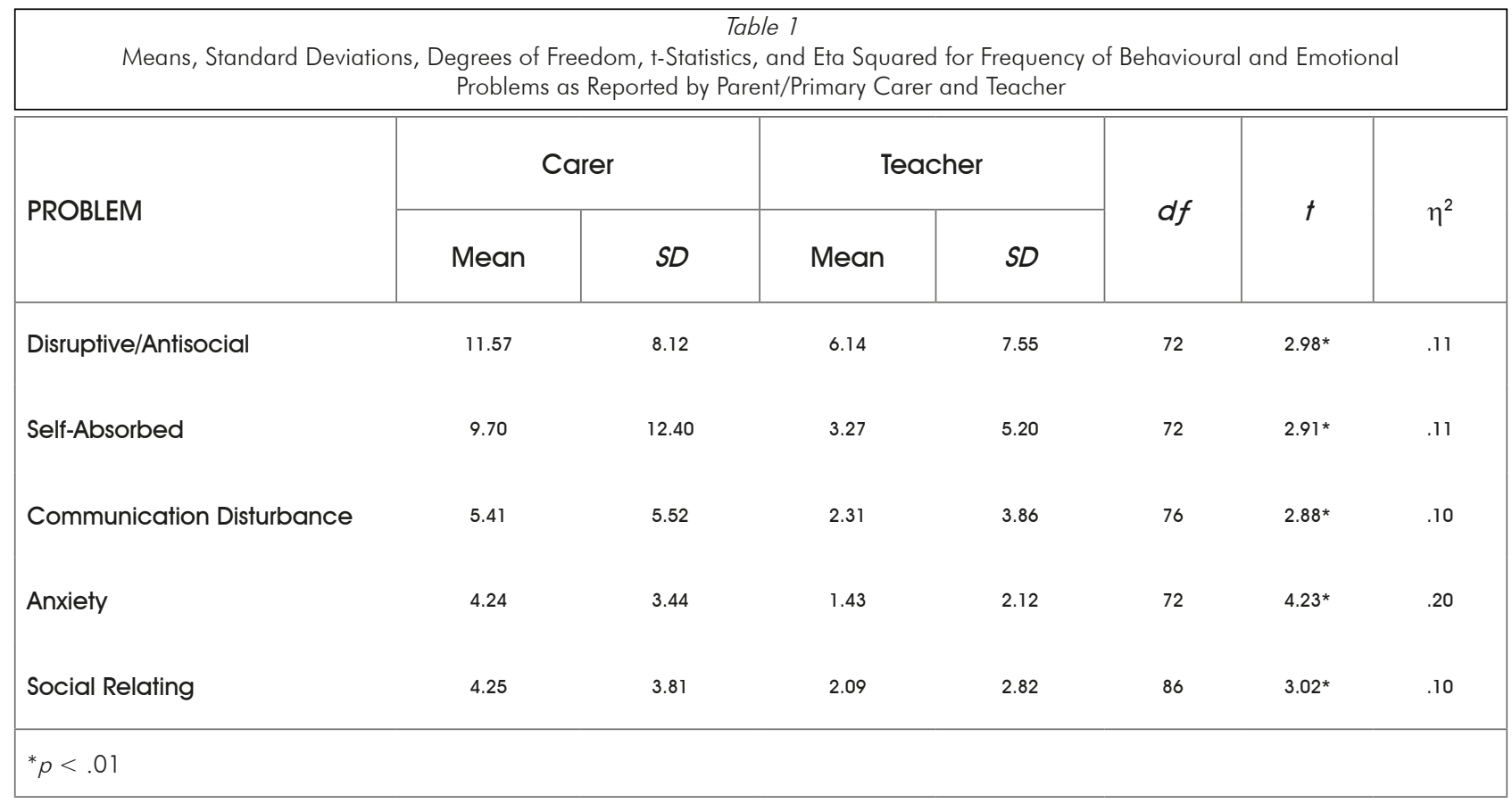


Table 2

Prevalence of Significant Problems in Adolescents with Mild Intellectual Disability as Reported by Parent/Primary Carer and Teacher

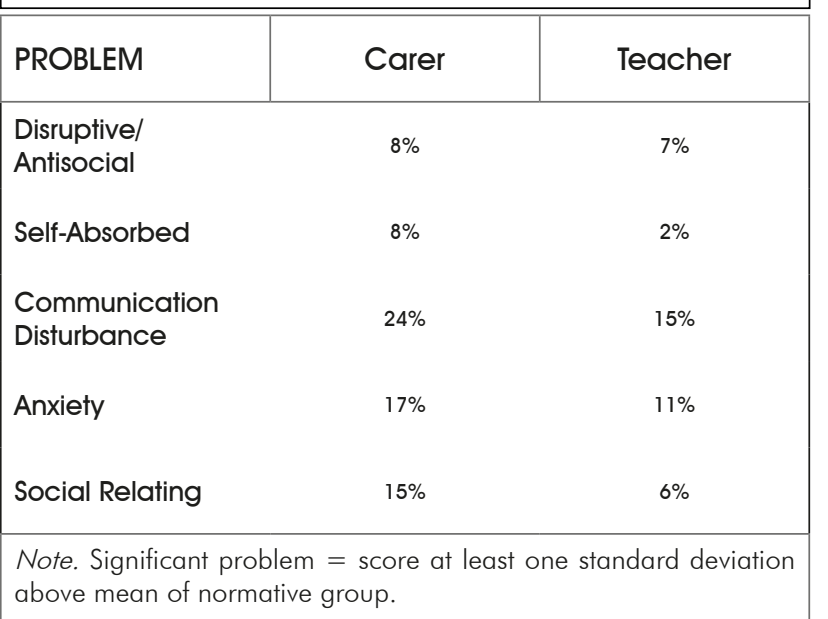

\section{DISCUSSION}

The overall aim of the present study was to examine the prevalence and severity of behavioural and emotional disturbances in adolescents with mild ID. An additional aspect of the study was to examine the extent of agreement between reports from the two primary groups of informants; parents and teachers. To be effective, intervention strategies need to be applied consistently across settings (Didden, 2007; Parmenter et al., 2007). Therefore, any programmes aimed at changing the behaviour of the adolescents would require collaboration between parents and teachers. Such collaboration is much more likely when both parties share a similar view of the nature of the problems that need to be addressed (Marsh \& Kersel, 2006).

Both primary carers and teachers rated the relative frequency of the five types of problems in the same order. They agreed that disruptive/ antisocial behaviours were the most common, followed by self-absorbed, communication disturbance, social relating, and that anxiety was the least frequent of the five types of challenging behaviour. This finding of both parents and teachers agreeing that disruptive/ antisocial behaviours are the most common type of problem is consistent with the findings reported by Einfeld and Tonge (2002), and it suggests that it may be possible to get agreement between parents and teachers on priorities for intervention.
The finding that disruptive/antisocial behaviours are the most common problem is also consistent with previous research findings that such behaviours are more prominent in people with mild ID (Dekker et al., 2002; Dykens, 2000; Einfeld \& Tonge, 1996b; Molteno et al., 2001). Koskentausta and Almqvist (2004) and Koskentausta et al. (2007) found that scores on externalising scales which measure behavioural problems involving conflict with others, rude rule-breaking and aggressive behaviours, were more common in children with mild ID as compared to those with moderate, severe or profound ID. Einfeld and Tonge (2002) have consistently found that on the DBC, scores on the Disruptive/Antisocial subscale decrease as degree of ID increases.

Despite agreement on the relative frequency of the five types of challenging behaviour, primary carers rated the adolescents as having a higher absolute frequency on all five subscales of the DBC. Therefore, carers reported more frequent occurrence of all the behaviours. These findings are consistent with the results reported by Dekker et al. (2002) and Einfeld and Tonge (2002), where it was found that carers rate problem behaviours as occurring significantly more frequently than teachers do.

There are a few possible explanations for this finding. Adolescents with mild ID may behave differently at home and in school so that respondents see different behaviours (Einfeld \& Tonge, 2002). They may be more at ease at home and more comfortable in their relationships with their carers than with their teachers. As such, they may be less reserved with emotional and behavioural expressions at home than at school. Alternatively, carers and teachers may view the adolescents' behaviours differently due to differences in rules and expectations of the standards of behaviour. Dekker et al. (2002) suggested that teachers compare students with their classmates who are all within similar ranges of intellectual functioning, as opposed to carers who compare the student with ID with other typically developing children. Due to their specialized training in the classroom management of students with special needs, teachers may consider the behaviours and emotions displayed by the adolescents to be 
less problematic than parents do. Finally, the structured environment in school may also help in reducing problematic behaviours as the environment appears to be more important than mild ID in determining challenging behaviour (Didden, 2007; Dworschak et al., 2016; Jacobs et al., 2016).

The present study found the overall rate of significant behavioural and emotional difficulties to be $22 \%$ and $27 \%$, as reported by parents/ primary carers and teachers, respectively. The results from the teachers' reports are similar to the $31 \%$ rate on the DBC reported by Molteno et al. (2001) in their study of 355 children with ID in special schools in Cape Town, South Africa. Unfortunately, the fact that in the present study not all respondents supplied enough information to allow for the calculation of this total score limits the generalizability of these findings.

Across the five types of challenging behaviour primary carers and teachers rated communication disturbance, when present, to be the most severe problem. Therefore, although disruptive/antisocial and selfabsorbed behaviours were more common, it was communication disturbance that was more likely to be a significant problem. The Communication Disturbance subscale of the $\mathrm{BDC}$ is a measure of communication deviance. Sample items that load on the subscale include: arranges objects or routine in a strict order, echoes others, talks to self, confuses the use of pronouns, repeats words or phrases, speaks with unusual tone or rhythm, does not mix with own age group peers, and preoccupies self with only one or two interests (Einfeld \& Tonge, 2002). This finding suggests that those adolescents with communication problems are more likely to have severe communication problems. Unfortunately, problems in communication have a significant impact on the quality of life and employment prospects for adolescents with ID (Parmenter at al., 2007). Similarly, although anxiety was reported to be the least frequent problem, when it was present it was more likely to be severe in nature than disruptive/antisocial, self-absorbed, or social relating problems. Other researchers have also noted the importance of assessing for anxiety disorders in young people with ID (e.g., Reardon et al., 2015).
Despite the failure of some parents/primary carers and teachers to complete the measure in full, the use of this ID-specific assessment has provided some useful findings. Carers and teachers agree on the relative frequency and severity of a range of challenging behaviour within this group of adolescents with mild ID. This means that it should be relatively easy to get agreement between parents and teachers on the priorities for intervention, thereby increasing the chances that any intervention will be carried out consistently across settings which, in turn, significantly increases the probability that the intervention will be successful. It is still unclear why carers report a higher frequency of problems than teachers. This may be a function of different expectations or training, or it may be that the frequency of the behaviours does indeed differ as a function of the home or school environment. While further research is needed to understand this finding, the other findings from the current study do provide confidence that parents/primary carers and teachers can be united in their focus as they work together to improve the quality of life for adolescents with mild ID.

\section{Conflict of interest}

The authors declare no conflict of interest.

\section{Acknowledgements}

The authors wish to thank the staff at both the Association for Persons with Special Needs and at Tanglin School in Singapore for assistance with data collection. An earlier version of this paper was presented at the VIII International Congress of Psychology and Education (CIPE 2016) in Alicante, Spain.

\section{REFERENCES}

Alimovic, S. (2013). Emotional and behavioural problems in children with visual impairment, intellectual and multiple disabilities. Journal of Intellectual Disability Research, 57, 153-160. doi: 10.1111/i.1365-2788.2012.01562.x

Cohen, J. W. (1988). Statistical power analysis for the behavioural sciences ( $2^{\text {nd }}$ ed.). Hillsdale, NJ: Lawrence Erlbaum Associates.

de Ruiter, K. P., Dekker, M. C., Douma, J. C. H., Verhulst, F. C., \& Koot, H. M. (2008). Development of parent- and teacher-reported emotional and behavioural problems in young people with intellectual disabilities: Does level of intellectual disability matter? Journal of Applied Research in Intellectual Disabilities, 21, 70-80. doi: 10.1111/i.1468-3148.2007.00370.x 
Dekker, M. C., Koot, H. M., van de Ende, J., \& Verhulst, F. C. (2002). Emotional and behavioral problems in children and adolescents with and without intellectual disability. Journal of Child Psychology and Psychiatry and Allied Disciplines, 43, 1087-1098. doi: 10.1111/1469-7610.00235

Didden, R. (2007). Functional analysis methodology in developmental disabilities. In P. Sturmey (Ed.), Functional analysis in clinical treatment (pp. 65-86). Burlington MA: Academic Press.

Dworschak, W., Ratz, C., \& Wagner, M. (2016). Prevalence and putative risk markers of challenging behavior in students with intellectual disabilities. Research in Developmental Disabilities, 58, 94-103. doi: 10.1016/i.ridd.2016.08.006

Dykens, E. M. (2000). Annotation: Psychopathology in children with intellectual disability. Journal of Child Psychology and Psychiatry and Allied Disciplines, 41, 407-417. doi: 10.1017/S0021963000005667

Einfeld, S. L., Ellis, L. A., \& Emerson, E. (2011). Comorbidity of intellectual disability and mental disorder in children and adolescents: A systematic review. Journal of Intellectual \& Developmental Disability, 36, 137-143. doi: 10.1080/13668250.2011.572548

Einfeld, S. L., \& Tonge, B. J. (1996a). Population prevalence of psychopathology in children and adolescents with intellectual disability: I. Rationale and methods. Journal of Intellectual Disability Research, 40, 91-98. doi: 10.1111/i.1365-2788.1996. tb00610.x

Einfeld, S. L., \& Tonge, B. J. (1996b). Population prevalence of psychopathology in children and adolescents with intellectual disability: II. Epidemiological findings. Journal of Intellectual Disability Research, 40, 99-109. doi: 10.1111/ j.1365-2788.1996.tb00611.x

Einfeld, S. L., \& Tonge, B. J. (2002). Manual for the Developmental Behaviour Checklist: Primary Carer Version (DBC-P) and Teacher Version (DBC-T) (2nd ed.). Melbourne, Australia: Monash University Centre for Developmental Psychiatry and Psychology.

Hassiotis, A., \& Turk, J. (2012). Mental health needs in adolescents with intellectual disabilities: Crosssectional survey of a service sample. Journal of Applied Research in Intellectual Disabilities, 25, 252 261. doi: $10.1111 /$ i.1468-3148.2011.00662.x

Jacobs, M., Woolfson, L. M., \& Hunter, S. C. (2016). Attributions of stability, control and responsibility: How parents of children with intellectual disabilities view their child's problematic behaviour and its causes. Journal of Applied Research in Intellectual Disabilities, 29, 58-70. doi: 10.1111/jar.12158

Jacobson, J. W. (1982). Problem behavior and psychiatric impairment within a developmentally disabled population I: Behavior frequency. Applied Research in Mental Retardation, 3, 121-139. doi: 10.1016/0270-3092(82)90002-9

Koskentausta, T., \& Almqvist, F. (2004). Developmental Behaviour Checklist (DBC) in the assessment of psychopathology in Finnish children with intellectual disability. Journal of Intellectual \& Developmental Disability, 29, 27-39. doi: $10.1080 / 13668250410001662883$

Koskentausta, T., livanainen, M., \& Almqvist, F. (2007). Risk factors for psychiatric disturbance in children with intellectual disability. Journal of Intellectual Disability Research, 51, 43-53. doi: 10.1111/i.13652788.2006.00871.x

Marsh, N. V., \& Kersel, D. A. (2006). Frequency of behavioural problems at one year following traumatic brain injury: Correspondence between patient and caregiver reports. Neuropsychological Rehabilitation, 16, 684-694. doi: 10.1080/09602010500220290

Molteno, G., Molteno, C. D., Finchilescu, G., \& Dawes, A. R. L. (2001). Behavioural and emotional problems in children with intellectual disability attending special schools in Cape Town, South Africa. Journal of Intellectual Disability Research, 45, 515-520.

Munir, K. M. (2016). The co-occurrence of mental disorders in children and adolescents with intellectual disability/intellectual developmental disorder. Current Opinion in Psychiatry, 29, 95-102. doi: 10.1097/ YCO.0000000000000236

Myrbakk, E., \& von Tetzchner, S. (2008). Psychiatric disorders and behavior problems in people with intellectual disability. Research in Developmental Disabilities, 29, 316-332. doi: 10.1016/i. ridd.2007.06.002

Pavlovic, M., Zunic-Pavlovic, V., \& Glumbic, N. (2013). Students' and teachers' perceptions of aggressive behaviour in adolescents with intellectual disability and typically developing adolescents. Research in Developmental Disabilities, 34, 3789. 3797. doi: 10.1016/i.ridd.2013.07.035

Parmenter, T. R., Harman, A. D., Yazbeck, M., \& Riches, V. C. (2007). Life skills training for adolescents with intellectual disabilities. In A. Carr, G. O'Reilly, P. N. Walsh, \& J. McEvoy (Eds.), The handbook of intellectual disability and clinical psychology practice (pp. 687-728). Hove, UK: Routledge.

Reardon, T. C., Gray, K. M., \& Melvin, G. A. (2015). Anxiety disorders in children and adolescents with intellectual disability: Prevalence and assessment. Research in Developmental Disabilities, 36, 175 190. doi: 10.1016/i.ridd.2014.10.007

Ruddick, L., Davies, L., Bacarese-Hamilton, M., \& Oliver, C. (2015). Self-injurious, aggressive and destructive behaviour in children with severe intellectual disability: Prevalence, service need and service receipt in the UK. Research in Developmental Disabilities, 45-46, 307-315. doi: 10.1016/i. ridd.2015.07.019

SPSS Inc. (2009). PASW statistics 18 brief guide. Chicago: Author.

Sturmey, P. (2007). Diagnosis of mental disorders in people with intellectual disabilities. In N. Bouras \& G. Holt (Eds.), Psychiatric and behavioural disorders in intellectual and developmental disabilities (pp. 3-23). New York, NY: Cambridge University Press. 
Tasse, M. J., \& Lecavalier, L. (2000). Comparing parent and teacher ratings of social competence and problem behaviors. American Journal of Mental Retardation, 105, 252-259. doi: 10.1352/08958017(2000)105<0252: CPATRO>2.0.CO:2

Tonge, B. (2007). The psychopathology of children with intellectual disabilities. In N. Bouras \& G. Holt (Eds.), Psychiatric and behavioural disorders in intellectual and developmental disabilities (pp. 93112). New York, NY: Cambridge University Press.

White, P., Chant, D., Edwards, N., Townsend, C., \& Waghorn, G. (2005). Prevalence of intellectual disability and comorbid mental illness in an Australian community sample. Australian and New Zealand Journal of Psychiatry, 39, 395-400. doi: 10.1080/i.1440-1614.2005.01587.x
Whitaker, S., \& Read, S. (2006). The prevalence of psychiatric disorders among people with intellectual disabilities: An analysis of the literature. Journal of Applied Research in Intellectual Disabilities, 19, 330-345. doi: 10.1111/i.14683148.2005.00293.x

Winterbottom, M., Smith, S., Hind, S., \& Haggard, M. (2008). Understanding similarities and differences between parents' and teachers' construal of children's behaviour. Educational Studies, 34, 483-510. doi: 10.1080/03055690802288452

Revista de Psicología y Educación / Journal of Psychology and Education, 2017, 12(2), 76-84 www.rpye.es Doi: https://doi.org/10.23923/rpye2017.12.146

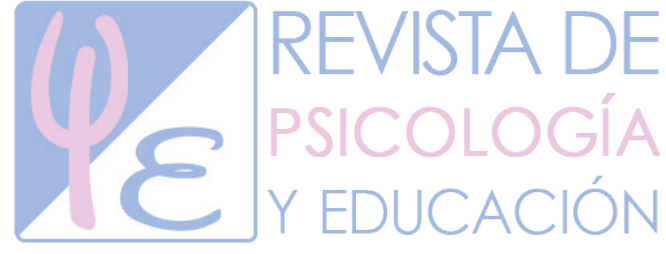

